\title{
An In Vitro Evaluation of the Inhibition of Recombinant Human Carboxylesterase-1 by Herbal Extracts
}

\author{
Hajra Mazhar, $\mathrm{PHD}^{1,2^{*}}$, Philippe Robaey, $\mathrm{MD}, \mathrm{PHD}^{2}$, Cory S. Harris, $\mathrm{PHD}^{1,3^{*}}$ \\ 'Department of Biology, University of Ottawa, Ottawa, Ontario, Canada K1N 9A7 \\ ${ }^{2}$ Children's Hospital of Eastern Ontario Research Institute, Ottawa, Ontario, Canada K1H 5B2 \\ ${ }^{3}$ School of Epidemiology and Public Health, University of Ottawa, Ottawa, Ontario, Canada K1G $5 Z 3$ \\ *@ Corresponding Authors: hmazh057@uottawa.ca; charris@uottawa.ca
}

\begin{abstract}
INTRODUCTION: Methylphenidate is a psychostimulant prescribed for symptoms of attention-deficit hyperactivity disorder (ADHD), and is metabolized by carboxylesterase-1 (CES1) enzyme. There is little information on herbal medicine used for ADHD and their interactions with CES1.

METHODS: An in vitro study was conducted with extracts of 21 herbal medicines using a recombinant human CES1 enzyme inhibition assay to determine if the extracts influence enzyme activity. Extracts were initially evaluated for their potential to inhibit CES1 metabolism of 4-nitrophenyl acetate using an in vitro Microtiter plate enzyme inhibition assay. The most active extracts were serially diluted to establish the half maximal inhibitory concentration $\left(I C_{50}\right)$ and were then tested for potential irreversible inhibition using a time-dependence enzyme assay. Phytochemical characterization of selected extracts was performed, and marker compounds were evaluated for their potential to inhibit CES1-mediated metabolism of the probe substrate.
\end{abstract}

RESULTS: The extracts exhibited a range of inhibition of CES1 activity, ranging from 15-95\% at a standard screening concentration of $200 \mu \mathrm{g} / \mathrm{mL}$. Rhodiola rosea was the most potent inhibitor of CES1 $\left(I C_{50}=4.7 \mu \mathrm{g} / \mathrm{mL}\right)$. No time-dependent inhibitors of CES1 were identified in this study. At $10 \mu \mathrm{g} / \mathrm{mL}$, marker compounds of ginger, [8]-gingerol (60.3\%) and [10]-gingerol (67.2\%), showed significant $(P<0.05)$ inhibition of CES1 compared to vehicle control.

DISCUSSION: The herbal medicine extracts showed varying inhibition at supraphysiologic concentrations and no risk of mechanism-based inhibition was observed. Herbal medicine used by ADHD patients have the potential to interact with CES1-mediated metabolism. To mitigate potential risk of herb-drug interactions, patients using herbal medicine alongside CES1-metabolized drugs should discuss their use with healthcare professionals.

CONCLUSIONS: In vivo and clinical research are required to determine if the potential interactions would significantly affect safety and efficacy of methylphenidate at a clinical level.

KEYWORDS: Adverse events; dietary supplements; drug metabolizing enzymes; herb-drug interactions; integrative medicine; natural health products; pharmacokinetics; polypharmacy

\section{Introduction}

Attention-deficit hyperactivity disorder (ADHD) is among the most prevalent childhood psychiatric disorders, globally affecting 5 to $7 \%$ of children and youth $[1,2]$. Psychostimulants (methylphenidate and salts of amphetamine) are first-line treatments and are generally effective at treating symptoms of ADHD but are associated with adverse events (AEs) [3].

Whereas amphetamine is metabolized by cytochrome P450 2D6 [4], methylphenidate is metabolized by human carboxylesterase-1 (CES1) [5]. CES1 is a serine hydrolase enzyme, belonging to the multi-gene family 
of $\alpha / \beta$ hydrolase fold proteins [6], and is responsible for metabolism of endogenous and exogenous substances including esters, amides, and thioesters [7, 8]. CES1 is primarily expressed in the liver, but also in the intestine, kidneys, and lungs to a lower extent [9], and selectively hydrolyses substrates with small alcohol groups, or large acyl groups [10]. CES1 converts methylphenidate to its inactive metabolite, ritalinic acid (Figure 1) [5].

Herbal medicines are one of the most commonly used form of natural health products (NHPs; dietary supplements in the United States) by children with ADHD [11], and among the most common NHPs used concurrently with psychostimulants [12]. Herbal medicines are chemically complex and contain substances that, when used concurrently with prescription medication, may interfere with drug metabolism, transport, or action and lead to herb-drug interactions that can potentially cause AEs [13].

Several studies demonstrated that many herbal medicines used to manage ADHD symptoms inhibit and/ or induce cytochrome P450 (CYP P450) enzymes [14]. Goldenseal, traditionally used as an anti-inflammatory for infections [15], is an inhibitor of CYP 3A4 and CYP 2D6 in vitro and in vivo [16]. However, with only a few in vitro studies examining the inhibitory potential of NHPs, the impact of herbal medicines on CES1 activity remains largely unexplored for potential herbdrug interactions [17]. Sun et al. (2016) [18] reported that the constituents of Psoralea (used widely in Asia for asthma, diarrhea, and osteoporosis) were inhibitors of CES1-mediated metabolism in vitro in human liver microsomes (HLM). Among these, the flavonoids and their derivatives neobavaisoflavone, corylifolinin, coryfolin, and corylin inhibited CES1 non-competitively, with respective inhibitory constant $\left(\mathrm{K}_{\mathrm{i}}\right)$ of $5.3,9.4,1.9$, and $0.7 \mu \mathrm{M}$. Oleanolic acid and urosolic acid, widely distributed in herbal medicines, were identified as potent inhibitors of CES1 metabolism, with half maximal inhibitory concentration $\left(\mathrm{IC}_{50}\right)$ values of 0.28 and $0.24 \mu \mathrm{M}$, respectively [19]. Black cohosh showed strong competitive inhibition ( $\mathrm{K}_{\mathrm{i}}: 1.62 \mathrm{mg} / \mathrm{mL}$ ) of CES1mediated bioactivation of irinotecan, an anti-cancer prodrug, in HLM [20]. Liu et al. (2010) [21] reported extracts of goldenseal strongly inhibit (75\%), and aqueous extracts of echinacea to mildly inhibit (18\%) HLMmediated metabolism of oseltamivir. HLM-mediated metabolism studies are usually specific to the substrate used, and may not be generalizable to other CES1 substrates. However, from a limited number of studies, there is some evidence that medicinal plants can interfere with CES1, potentially altering the metabolism of methylphenidate, resulting in changes in efficacy or safety.

Time-dependent inhibition, also known as mechanism-based or irreversible inhibition, occurs with the covalent binding of a chemically reactive intermediate to the enzyme and results in loss of enzyme activity only recovered with de novo production of the enzyme. Timedependent inhibition results in stronger inhibition when the inhibitor is pre-incubated with the enzyme before the addition of substrate $[22,23]$. A well-known example is the irreversible inhibition of CYP $3 \mathrm{~A} 4$ by furanocoumarins in grapefruit $\left(6^{\prime}, 7^{\prime}\right.$-dihydroxybergamottin and bergamottin) that, when consumed concurrently with substrate drugs, can lead to increased blood levels of the drug with potential to cause AEs in patients if blood levels move beyond the therapeutic window into the toxic range [24]. Though not widely studied with herbal medicine [25] and rarely studied with respect herb-CES1 interactions, time-dependent inhibitors are common among serine hydrolases, and can cause serious AEs in clinical settings [26]. Consequently, due

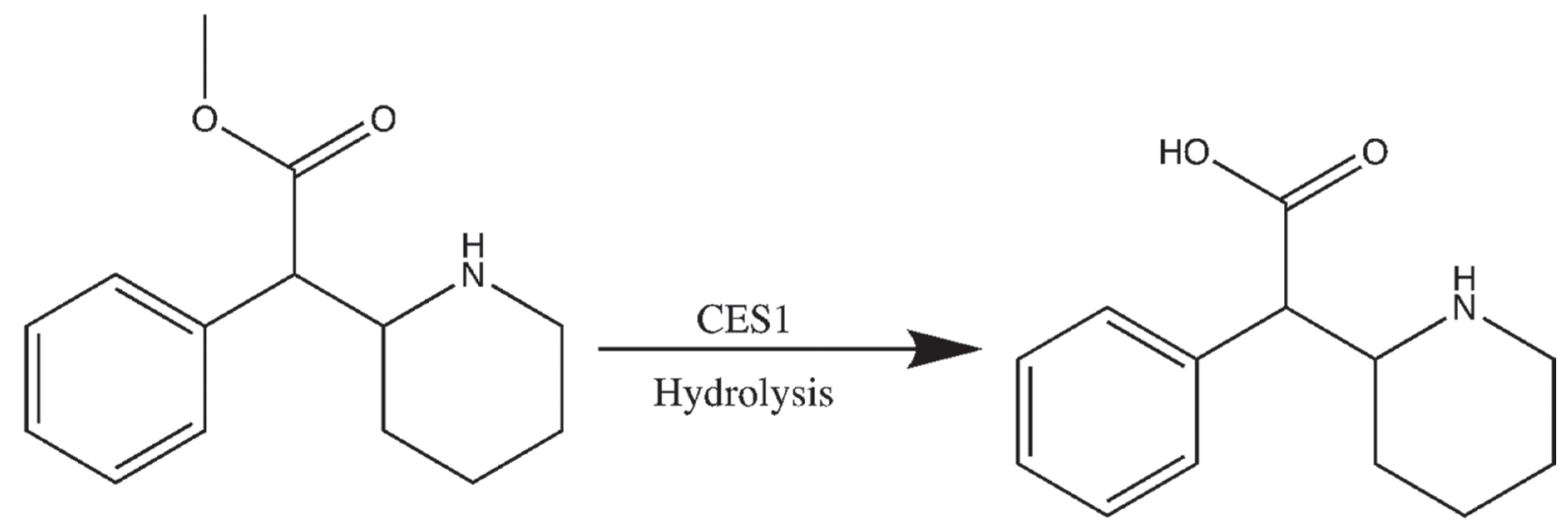

Methylphenidate

Ritalinic acid

Figure 1. Major pathway of the metabolism of methylphenidate in humans. 
to the complex chemical nature of herbal medicines, it is important to understand if and how they interact with CES1.

Although limited clinical research has been conducted on the use of herbal medicine specifically for $\mathrm{ADHD}$, in a previous review [14], we identified 21 herbal medicines used by children with neurological disorders, including ADHD. Many of these herbal medicine have not been studied extensively for effects on CES1-mediated metabolism [17] so their potential for interactions with methylphenidate remain unknown.

To assess the potential risk of herb-drug interactions related to concurrent use of herbal medicine with CES1 substrates, such as methylphenidate, herbal extracts were evaluated in vitro for inhibitory effects on the activity of CES1. For the most active extracts, the inhibitory potency was determined, followed by assessment of inhibitory potential of their marker compounds. The mode of inhibition of these extracts was investigated using time-dependent assays and comparison to a known irreversible (JZL184) and reversible competitive inhibitor (oseltamivir) of CES1 [27, 28]. JZL 184 is a carbamate compound known for irreversible inhibition of the serine hydrolase family through covalent modification of the active site [27]. Oseltamivir is an anti-viral ester prodrug activated through CES1-mediated biotransformation to the active hydrolytic metabolite, oseltamivir carboxylate [28].

\section{Methods}

\section{Chemicals and Reagents}

Recombinant human CES1 was purchased from Corning Life Sciences (Tewksbury, U.S.A.). Oseltamivir, 4-nitrophenyl acetate (4-NA), Tris, bilobalide, menthol and rosmarinic acid were purchased from SigmaAldrich (Oakville, Canada). JZL184 was obtained from Cayman Chemical Company (Ann Arbor, U.S.A.). Rosarin, rosavin, rosin, salidroside and tyrosol were purchased from ChromaDex (Los Angeles, U.S.A.). [6], [8], and [10]-gingerol, ginkgolide $\mathrm{A}$ and ginkgolide $\mathrm{B}$ were purchased from Extrasynthese (Genay, France). All solvent used in chromatographic analysis were HPLC grade from Fisher Scientific (Ottawa, Canada).

\section{Commercial Plant Extracts and Tinctures}

A targeted selection of 21 commercial grade tinctures were generously provided by St. Francis Herb Farm (Combermere, Canada). The label information of these tinctures are presented in Table 1.

For each tincture, $30 \mathrm{~mL}$ was weighed then dried using a Labconnco Centrivap Concentrator with a Centrivap
Cold Trap to remove alcohol and an EC Modulyo Freeze Drier (Thermo Electron, Ottawa, Canada) to remove remaining water. Dried extracts were weighed and stored in darkness at $-20^{\circ} \mathrm{C}$ until use. A $10 \mathrm{mg}$ aliquot of each dried extract was reconstituted in $20 \%$ acetone and filtered using $0.2 \mu \mathrm{m}$ PTFE filters to obtain $10 \mathrm{mg} / \mathrm{mL}$ stock solutions. Stock solutions were vortexed and sonicated to ensure homogeneity before use.

\section{CES1 Inhibition Assay}

Preliminary evaluation of herbal medicine extracts

A Microtiter plate assay was used to evaluate the inhibitory potential of commercial plant extracts towards recombinant CES1-mediated metabolism of 4-NA. The procedure from R\&D Systems based on Ajandouz et al. (2016) [29] and Murakami et al. (2010) [30] was adapted and modified to include herbal medicine extract as a test sample (R\&D Systems, n.d.). The assays were performed in 96-well clear-bottom Microtiter plates (Corning Costar) and absorbance was measured using a Cytation 3 cell Imaging Multi-Mode Reader (BioTek Instruments Inc., Winooski, U.S.A.).

The chromogenic probe substrate 4-NA was used for rapid monitoring and quantification of CES1 activity. Samples were incubated in the presence (test) and absence (test-blank) of recombinant CES1 $(6.5 \mathrm{nM})$ and 4 -NA $(1 \mathrm{mM})$ in $50 \mathrm{mM}$ Tris buffer at a $\mathrm{pH}$ of 7.5 at $37^{\circ} \mathrm{C}$. JZL184 $(2 \mu \mathrm{M})$ was used as a positive control and $20 \%$ acetone was used as vehicle control (VC-final well concentration: $2 \%$ ). The total assay volume was $100 \mu \mathrm{L}$. The plate was incubated for 15 minutes at $37^{\circ} \mathrm{C}$ after the addition of CES1. Absorbance readings were taken at $405 \mathrm{~nm}$ to determine the rate of formation of 4-nitrophenol from the hydrolysis of 4-NA.

The positive and negative control incubations were carried out under the same conditions. All samples were tested in triplicate in three independent experiments. Percent inhibition was measured using the difference in absorption between test/test-blank wells and the mean difference between the test/test-blank wells.

\section{Concentration-dependent response curves}

Ginger, ginkgo, peppermint, and rhodiola exhibited the strongest inhibition relative to the $\operatorname{VC}(P<0.05)$ in the preliminary evaluation (Figure 2 ), and were tested for concentration-dependent response analysis. Rosemary extract was also further tested as it approached significance relative to vehicle control $(P=0.053)$ in the initial evaluation. Serial dilutions of stock solutions were performed for the 5 tinctures to yield six to ten concentrations $(0.8 \mu \mathrm{g} / \mathrm{mL}-200 \mu \mathrm{g} / \mathrm{mL}$, ) to evaluate concentrationdependent response and determine the $\mathrm{IC}_{50}$. 
Table 1. List of herbal medicine tested in this study.

\begin{tabular}{|c|c|c|}
\hline $\begin{array}{l}\text { Botanical common name } \\
\text { (Scientific name) }\end{array}$ & Plant part & $\begin{array}{l}\text { Standardized quantity per } \mathrm{mL} \\
\text { (Quantity crude equivalent ratio) }\end{array}$ \\
\hline Bacopa (Bacopa monnieri) & Whole plant & $250 \mathrm{mg}(1: 4)$ \\
\hline Chamomile (Matricaria chamomilla) & Flower & $250 \mathrm{mg}(1: 4)$ \\
\hline Echinacea (Echinacea angustifolia) & Roots, rhizome & $250 \mathrm{mg}(1: 4)$ \\
\hline Echinacea (Echinacea purpurea) & Flower, leaf, root & $1000 \mathrm{mg}(1: 1)$ \\
\hline \multirow[t]{2}{*}{ Echinacea (Echinacea angustifolia + Echinacea purpurea) } & Root, rhizome & $667 \mathrm{mg}$ per $0.67 \mathrm{~mL}(1: 1)$ \\
\hline & Tops, roots & 83 mg per 0.33 mL (1:4) \\
\hline Eleuthero (Eleutherococcus senticosus) & Root & $250 \mathrm{mg}(1: 4)$ \\
\hline Garlic (Allium sativum) & Bulb & $250 \mathrm{mg}(1: 4)$ \\
\hline Ginger (Zingiber officinale) & Rhizome & 1000 mg (1:1) \\
\hline Ginkgo (Ginkgo biloba) & Leaf & $250 \mathrm{mg}(1: 4)$ \\
\hline Goldenseal (Hydrastis canadensis) & Roots, rhizome & $200 \mathrm{mg}(1: 5)$ \\
\hline Green tea (Camellia sinensis) & Leaf & $250 \mathrm{mg}(1: 4)$ \\
\hline Kava (Piper methysticum) & Dried rhizome & $250 \mathrm{mg}(1: 4)$ \\
\hline Lemon balm (Melissa officinalis) & Tops & $250 \mathrm{mg}(1: 4)$ \\
\hline Linden (Tilia cordata) & Dried flower & $250 \mathrm{mg}(1: 4)$ \\
\hline Passion flower (Passiflora incarnata) & Tops & $250 \mathrm{mg}$ dry $(1: 4)$ or $1000 \mathrm{mg}$ fresh (1:1) \\
\hline Peppermint (Mentha x piperita) & Leaf & $250 \mathrm{mg}(1: 4)$ \\
\hline Rhodiola (Rhodiola rosea) & Root & $250 \mathrm{mg}(1: 4)$ \\
\hline Rosemary (Rosmarinus officinalis) & Leaf & $250 \mathrm{mg}(1: 4)$ \\
\hline Scullcap (Scutellaria lateriflora) & Flowering top & 250 mg (1:4) \\
\hline St. John's wort (Hypericum perforatum) & Flowering top & $250 \mathrm{mg}(1: 4)$ \\
\hline Valerian (Valeriana officinalis) & Root & $250 \mathrm{mg}$ dry $(1: 4)$ or $1000 \mathrm{mg}$ fresh (1:1) \\
\hline
\end{tabular}

\section{Irreversible time-dependent kinetic activity}

Irreversible inhibition was assessed in vitro for extracts of ginger, ginkgo, peppermint, rosemary, and rhodiola using time-dependent assays with the pre-incubation method described by Yamamoto et al. (2002) [31]. Two solutions were prepared: the pre-incubation solution contained sample (JZL184, oseltamivir, or plant extract) and CES1 $(6.5 \mathrm{nM})$ in $50 \mathrm{mM}$ tris buffer (pH: 7.5). The reaction solution contained $4-\mathrm{NA}(1 \mathrm{mM})$ in $50 \mathrm{mM}$ tris buffer (pH: 7.5). After 0, 5, and 10, minutes of preincubation at $37^{\circ} \mathrm{C}$, the reaction solutions were added to the pre-incubation solutions (total volume: $100 \mu \mathrm{L}$ ). The absorbance from the metabolism of 4-NA was measured after 15 minutes of incubation to determine the residual activity of CES1 relative to VC. The kinetic response of extracts $(40 \mu \mathrm{g} / \mathrm{mL})$ was compared to JZL184 $(0.5 \mu \mathrm{g} / \mathrm{mL})$, and oseltamivir $(1 \mathrm{mg} / \mathrm{mL})$.

\section{Evaluation of marker compounds for CES1 inhibition}

Select standard marker compounds of rhodiola (rosarin, rosavin, rosin, salidroside, tyrosol), rosemary (rosmarinic acid), peppermint (menthol), ginger ([6]-gingerol, [8]-gingerol, [10]-gingerol), and ginkgo (quercetin, bilobalide, ginkgolide $\mathrm{A}$, and ginkgolide $\mathrm{B}$ ) were evaluated at $10 \mu \mathrm{g} / \mathrm{mL}$ for their ability to inhibit CES1-mediated metabolism in vitro using the CES1 inhibition assay methods described above.

\section{Phytochemical Analysis of Extracts}

High-performance liquid chromatography with diode array detector (HPLC-DAD) was used to analyze extracts of ginger, rosemary, rhodiola, and ginkgo. An Agilent 1100 HPLC system was used for analysis. The system consisted of an autosampler (G1313A with $100 \mu \mathrm{L}$ loop), Quaternary pump (G1311A), solvent degasser (G1322A), a column oven (G1316A), and a diode array detector (G1315A).

Separation of marker compounds in ginger, rosemary and rhodiola were performed on Phenomenex Synergi Max-RP $(250 \times 3 \mathrm{~mm} 4 \mu$ particle size $)$. Mobile phase A was $0.1 \%$ trifluoroacetic acid in water, and mobile phase $\mathrm{B}$ was $0.1 \%$ trifluoroacetic acid in acetonitrile. The injection volume was $1 \mu \mathrm{L}$, and the column oven temperature was set at $55^{\circ} \mathrm{C}$. The flow rate was $0.5 \mathrm{~mL} /$ minute and the DAD was set to $280 \mathrm{~nm}$ to $350 \mathrm{~nm}$.

For ginger, the gradient initiated with $5 \% \mathrm{~B}$ for 1 minute and increased to $100 \%$ in 17 minutes. The gradient was held at $100 \%$ B for 7 minutes, followed by a 5-minute re-equilibration period. For rosemary and rhodiola, the gradient initiated with $10 \% \mathrm{~B}$, and increased 


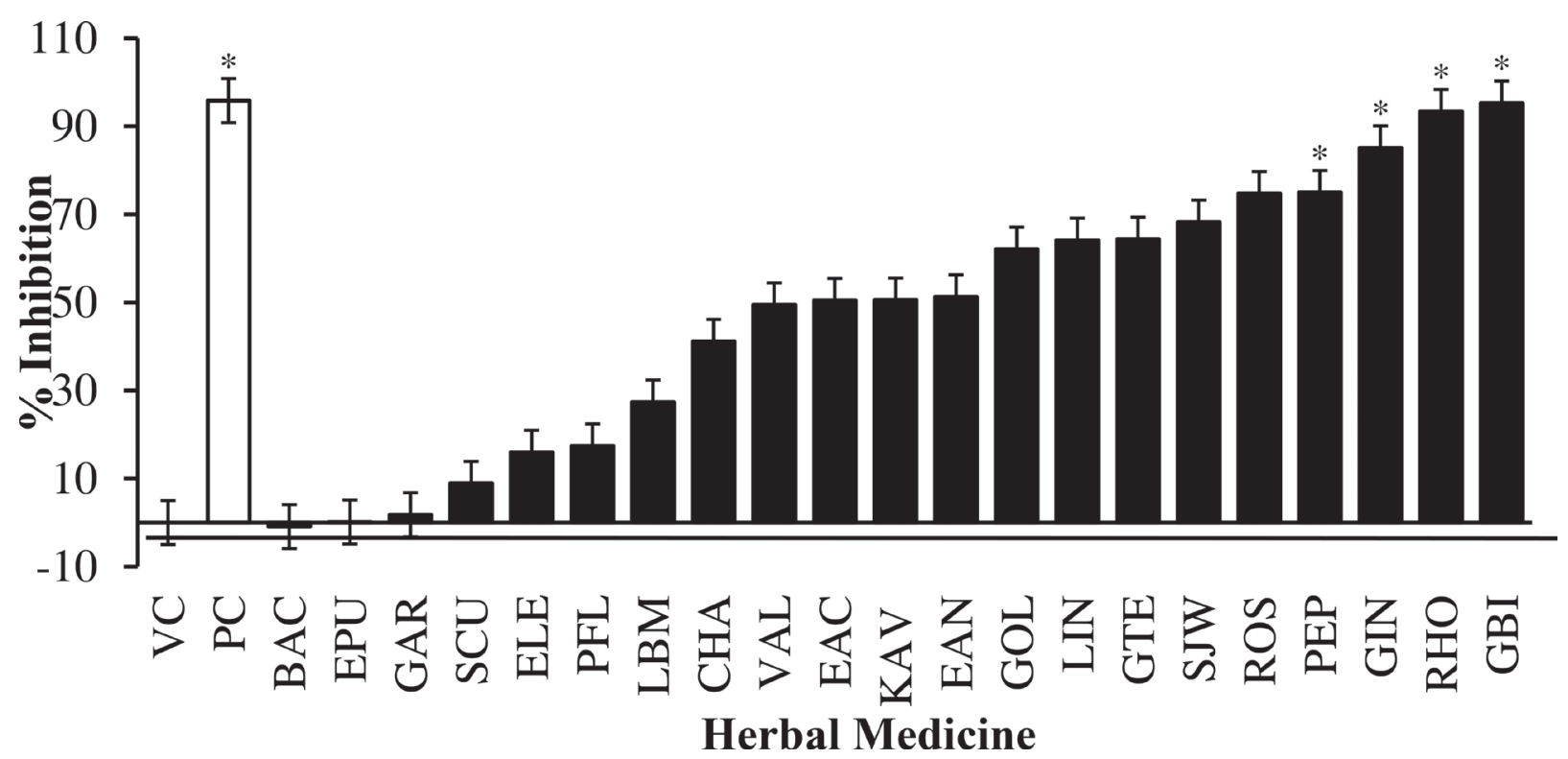

Figure 2. The inhibitory effect of 21 extracts of commercial herbal tinctures ( $200 \mu \mathrm{g} / \mathrm{mL}$ ) on carboxylesterase-1 mediated metabolism of 4-nitrophenyl acetate. JZL184 (2 $\mathrm{MM}$ or $1 \mu \mathrm{g} / \mathrm{mL}$ ) was used as positive control (PC). Percent inhibition was calculated relative to vehicle control (VC: $2 \%$ acetone final concentration). Means \pm SEM are presented for three independent trials. Significant differences between extracts $(P<0.05)$ are denoted by *, as determined by Kruskal-Wallis one-way analysis of variance on ranks, with Dunn's post hoc analysis. (BAC) bacopa; (EPU) Echinacea purpurea; (GAR) garlic; (SCU) skullcap; (ELE) eleuthero; (PFL) passion flower; (LBM) lemon balm; (CHA) chamomile; (VAL) valerian; (EAC) EchinAce; (KAV) kava, (EAN) Echinacea angustifolia; (GOL) goldenseal; (LIN) linden; (GTE) green tea; (SJW) St. John's wort; (ROS) rosemary; (PEP) peppermint; (GIN) ginger; (RHO) rhodiola; and (GBI) Ginkgo.

to $50 \% \mathrm{~B}$ in 19 minutes. The gradient was increased to $100 \%$ B over 5 minutes, and kept at this condition for 5 minutes, followed 5 by minutes of re-equilibrium.

Separation of ginkgo was performed on Phenomenex Luna C18 column $(150 \times 2 \mathrm{~mm}, 3 \mu$ particle size $)$. Mobile phase A was water, and mobile phase B was methanol, with a flow rate of $0.3 \mathrm{~mL} / \mathrm{min}$. Mobile phase B was held at $25 \%$ for 1 minute, increased to $100 \%$ over 24 minutes, held at $100 \%$ for 10 minutes, and reduced to $25 \%$ at 35.1 minutes. The column was equilibrated for 7 minutes. The detector was set to $210 \mathrm{~nm}-330 \mathrm{~nm}$ at $55^{\circ} \mathrm{C}$. The injection volume was $10 \mu \mathrm{L}$.

Gas chromatography with flame ionization detector (GC-FID) was used to analyse extracts of peppermint. The method to identify menthol was adapted by Lee (2019) [32] from Supelco Analytical Products (Munich, Germany). Briefly, $1 \mu \mathrm{L}$ of peppermint extract $(1 \mathrm{mg} / \mathrm{mL}$ in $99 \%$ ethanol) was injected on Agilent $6890 \mathrm{~N}$ Network Gas Chromatogram with an autosampler (7683 series) and dual injector (7683 series) with a FID and SLB-5MS GC Column $(30 \mathrm{~m} \times 0.25 \mathrm{~mm} \times 0.25 \mu \mathrm{m})$. The injector temperature was $230^{\circ} \mathrm{C}$. The oven was set to $60^{\circ} \mathrm{C}$ for 3.5 minutes, $3.5^{\circ} \mathrm{C} /$ minute to $155^{\circ} \mathrm{C}, 30^{\circ} \mathrm{C} /$ minute to $300^{\circ} \mathrm{C}$ with a post run at $340^{\circ} \mathrm{C}$ for 10 minutes. The carrier gas was hydrogen and was set at a flow rate of
$1.4 \mathrm{~mL} /$ minutes. Methanol standard was prepared at $250 \mu \mathrm{g} / \mathrm{mL}$ in $99 \%$ ethanol.

For both HPLC and GC, peak identification was confirmed through relative retention times of standard marker compounds with further confirmation through comparison of UV absorption spectra (for HPLC results only). All data was processed in ChemStation software (Version B 3.02).

\section{Statistics}

A Kruskal-Wallis one-way analysis of variance on ranks, followed by a Dunn's post hoc test was used to evaluate the non-parametric screening data (percent inhibition of CES1) to perform multiple comparisons between extracts and the vehicle control. $\mathrm{IC}_{50}$ values were obtained by plotting percent inhibition against log-transformed concentration $(\mathrm{mg} / \mathrm{mL})$ using the $\log [$ inhibitor] vs. normalized response-variable slope function on Prism GraphPad (version 8.1.0). For the time-dependent experiments, an ANOVA with Dunnett's post hoc test was performed to determine effects on the activity of CES1 when comparing 5-, 10-, or 15-minute preincubation times relative to the 0 -minute incubation for each inhibitor. A $P<0.05$ was considered significant for all comparisons. 


\section{Results}

\section{Preliminary evaluation of herbal medicine extracts}

Figure 2 displays the mean percent inhibition of CES1 for the 21 tested extracts at a supraphysiological concentration of $200 \mu \mathrm{g} / \mathrm{mL}$. Four of the extracts elicited strong inhibition relative to $\mathrm{VC}$ including ginkgo, rhodiola, ginger, and peppermint $(P<0.05)$. The rosemary extract approached significance with an average of $74 \%$ inhibition with $P=0.053$. The remaining extracts exhibited $0-68 \%$ inhibition.

\section{Concentration-dependent responses}

Figure 3 depicts the concentration response curves and the $\mathrm{IC}_{50}$ with the $95 \%$ confidence interval. Rhodiola was the most potent towards CES1 with an $\mathrm{IC}_{50}$ of $4.3 \mu \mathrm{g} / \mathrm{mL}$ $(P<0.05)$, followed by ginkgo $(22.2 \mu \mathrm{g} / \mathrm{mL})$, ginger $(53.2 \mu \mathrm{g} / \mathrm{mL})$, peppermint $(70.9 \mu \mathrm{g} / \mathrm{mL})$, and rosemary $(74.2 \mu \mathrm{g} / \mathrm{mL})$.

\section{Time-dependent kinetic activity}

In the time-dependent study (Figure 4), JZL184 displayed decreasing CES1 residual activity with increasing preincubation times, as expected. Significant differences were observed between the 0 and 5 -minute $(P<0.0001,95 \%$ CI: 9.2 to 28.4$), 0$ and 10 -minute $(P<0.0001,95 \%$ CI: 20.5 to 39.8$)$, and 0 and 15 -minute $(P<0.0001,95 \%$ CI: 31.2 to 50.5$)$ pre-incubation times for JZL184. In contrast and as expected, the residual activity of CES1 remained relatively constant with increasing time of pre-incubation with oseltamivir, a competitive inhibitor. No significant differences in CES1 activity were observed for ginger, peppermint, rhodiola, and rosemary extracts for pre-incubation times 5,10 , and 15 minutes relative to the 0 -minute pre-incubation time. A significant increase $(P<0.04,95 \% \mathrm{CI}:-30.6$ to 1.5) in CES1 residual activity was observed for ginkgo between the 0 and 10-minute pre-incubation times, but no significant differences were found between 5 -minute pre-incubation times relative to 0 minutes for ginkgo. Overall, no herbal time-dependent inhibitors of CES1 were identified in this study.

\section{Inhibition of CES1 by marker compounds}

Marker compounds of ginger, ginkgo, peppermint, rosemary, and rhodiola were tested for their inhibitory potential against recombinant CES1 at $10 \mu \mathrm{g} / \mathrm{mL}$ (Figure 5). Marker compounds of ginger, [8]-gingerol $(P=0.005$, 95\% CI: -107.8 to -12.8$)$, and [10]-gingerol $(P=0.002,95 \% \mathrm{CI}:-114.7$ to -19.7$)$, showed significant inhibition compared to vehicle control. [6]-gingerol inhibited CES1 by $24 \%$ but this was not statistically significant ( $P=0.77,95 \% \mathrm{CI}:-71.6$ to 23.4$)$. Marker compounds of ginkgo, rhodiola, rosemary and peppermint showed weak to zero inhibition. The positive control, JZL184, inhibited CES1 completely.

\section{Phytochemistry Marker Compounds}

Phytochemical profiling of extracts was performed to confirm the presence of marker compounds. HPLCDAD chromatogram in Figure $6 \mathrm{~A}-\mathrm{D}$ illustrates the presence of respective marker compounds in commercial extracts of ginger, ginkgo, rosemary, and rhodiola. Gas chromatography with flame-ionized detection (GC-FID) was used to confirm the presence of menthol in peppermint (Figure 6E).

\section{Discussion}

The use of herbal medicine by children with ADHD, especially those concurrently using the psychostimulant methylphenidate, is common [12]. Although licenced herbal medicines are generally considered safe to use, their safety profile when used concurrently with conventional drugs, especially those that are substrates of CES1, has not been studied extensively [33].

Our study demonstrated that the majority of the 21 tested herbal extracts showed some inhibition of CES1mediated metabolism of the probe substrate 4-NA at supraphysiological concentrations. Only a few other studies have examined the effects of these herbal medicine in CES1-mediated metabolism. Gorman et al. (2013) [20] found St. John's wort to be a weak inhibitor $(49.4 \mathrm{mg} / \mathrm{mL})$ of CES1-mediated metabolism of chemotherapeutic agent, irinotecan, in HLM. In the current study, St. John's wort displayed relatively moderate inhibition of recombinant CES1. However, in a passive monitoring of AEs, Mazhar et al. (2019) [34] found 2 reports involving St. John's wort and methylphenidate to be causally linked to be herb-drug interactions. Therefore, St. John's wort could have product-specific effects on CES1 inhibition, or could show varying inhibition based on the plant material or extract as well as the substrate or enzyme source used. Liu et al. (2010) [21] reported goldenseal to be a strong inhibitor $(75 \%$ inhibition), and the aqueous extract of Echinacea purpurea extract ( $18 \%$ inhibition) to be a relatively mild inhibitor of CES1-mediated metabolism of the antiviral drug, oseltamivir, in HLM. Our study, the first to target CES1 specifically using a human recombinant enzyme, showed Echinacea purpurea to have negligible inhibition and goldenseal to have $62 \%$ inhibition at a supraphysiological concentration $(200 \mu \mathrm{g} / \mathrm{mL})$. Variation in inhibition may reflect differences in experimental models or in phytochemistry of extracts due to a host of intrinsic (plant species and source) and extrinsic factors 

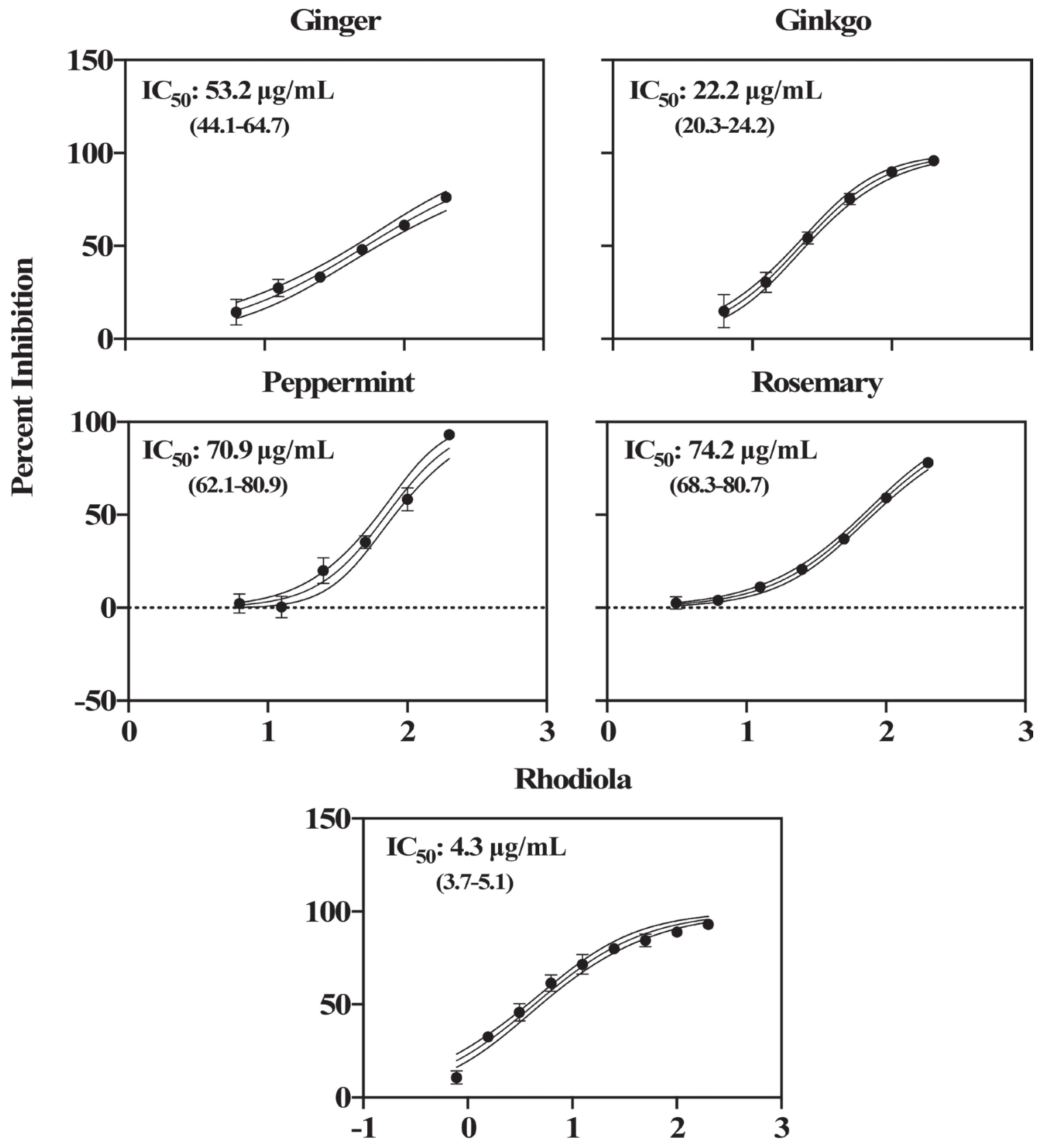

Log Concentration

Figure 3. The mean half maximal inhibitory concentration $\left(I_{50}\right)$ values and $95 \%$ confidence intervals for commercial extracts of ginger, ginkgo, rhodiola, rosemary, and peppermint on carboxylesterase-1 mediated metabolism of 4-nitrophenyl acetate. Concentrations were transformed into log form and percent inhibition was calculated relative to vehicle control ( $2 \%$ acetone final concentration), $(n=3)$. IC $C_{50}$ values were obtained using the $\log [$ inhibitor] vs. normalized response-variable slope function on Prism GraphPad (version 8.1.0).

(environment and growth conditions, extraction protocols, product processing and storage, contamination or adulteration) $[35,36]$. Nonetheless, like drugs, the dose and rate at which herbal medicines are consumed could be a factor in their safety.

Ginger has been reported as a strong inhibitor of CES1-mediated metabolism of irinotecan in HLM, with an indeterminate mode of inhibition [20]. Our study showed ginger to be a reversible inhibitor of CES1. Moreover, we reported that marker compounds of ginger, [6]-gingerol, [8]-gingerol, and [10]-gingerol, showed $24 \%-67 \%$ inhibition of CES1 activity at approximately $30 \mu \mathrm{M}$. The inhibition of CES1 by ginger-based products, as in our study, may be due to additive or synergistic inhibition by the gingerols and possibly other constituents. To our knowledge, other herbal products 


\section{$\mathrm{T}_{0} \quad \square \mathrm{T}_{5} \quad \square \mathrm{T}_{10} \mathbf{\mathrm { Q }} \mathrm{T}_{15}$}

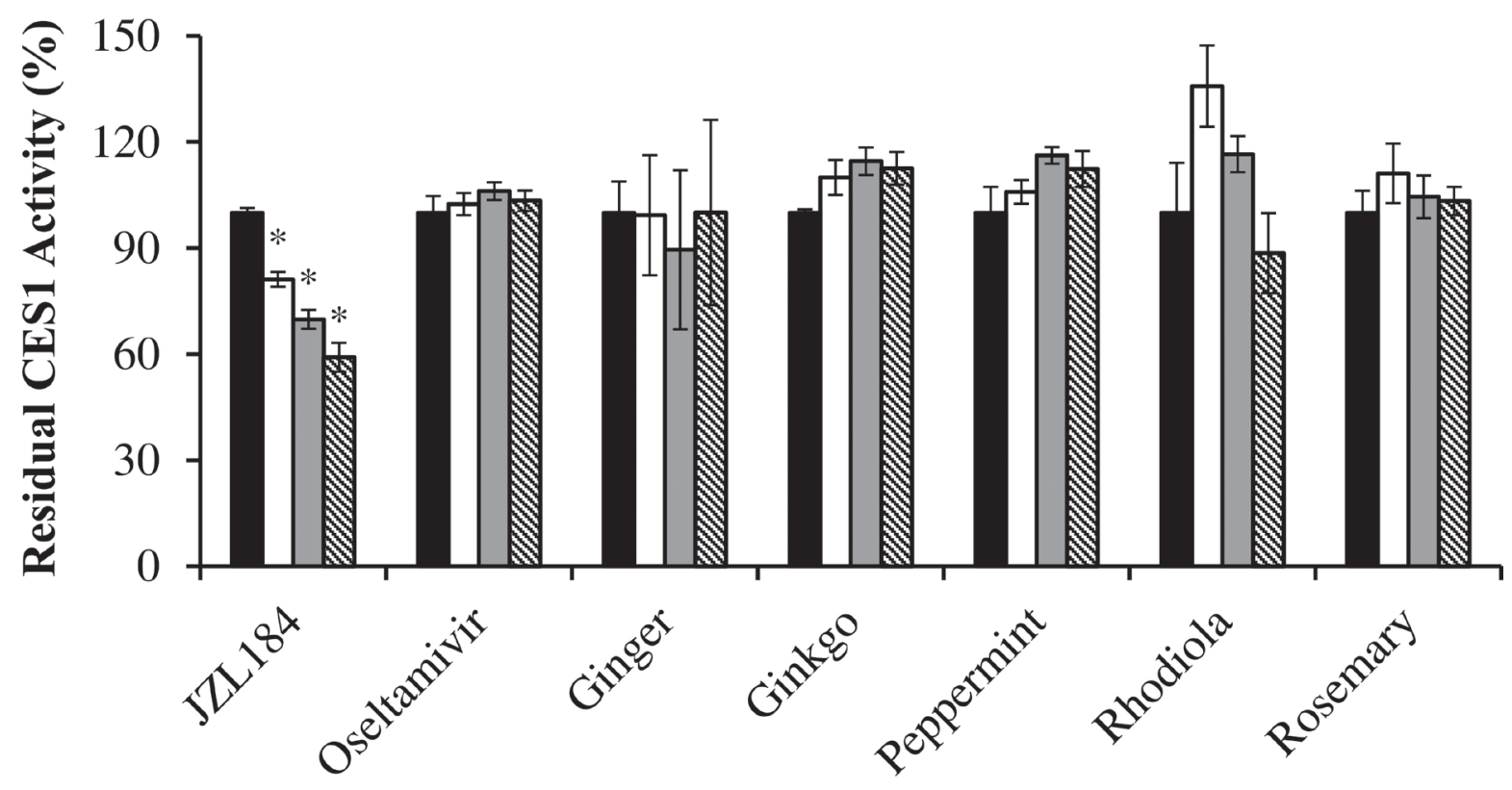

Herbal Medicine

Figure 4. Determining mode of inhibition for commercial herbal extracts on carboxylesterase-1 (CES1) mediated metabolism of 4-nitrophenyl acetate using a Microtiter assay. The activity of CES1 after pre-incubation with extracts $(0.04 \mathrm{mg} / \mathrm{mL})$, JZL184 $(0.5 \mu \mathrm{g} / \mathrm{mL})$, and oseltamivir $(1 \mathrm{mg} / \mathrm{mL})$ were compared at 0, 5,10, or 15-minute pre-incubation times. Values are shown as mean CES1 residual activity \pm SEM $(n=3)$. An ANOVA with Dunnett's post hoc was used to compare the differences in residual activity of time 0 vs. 5, 10 and 15-minute pre-incubation time for each control and extract. Significance is marked by * $(P<0.05)$.

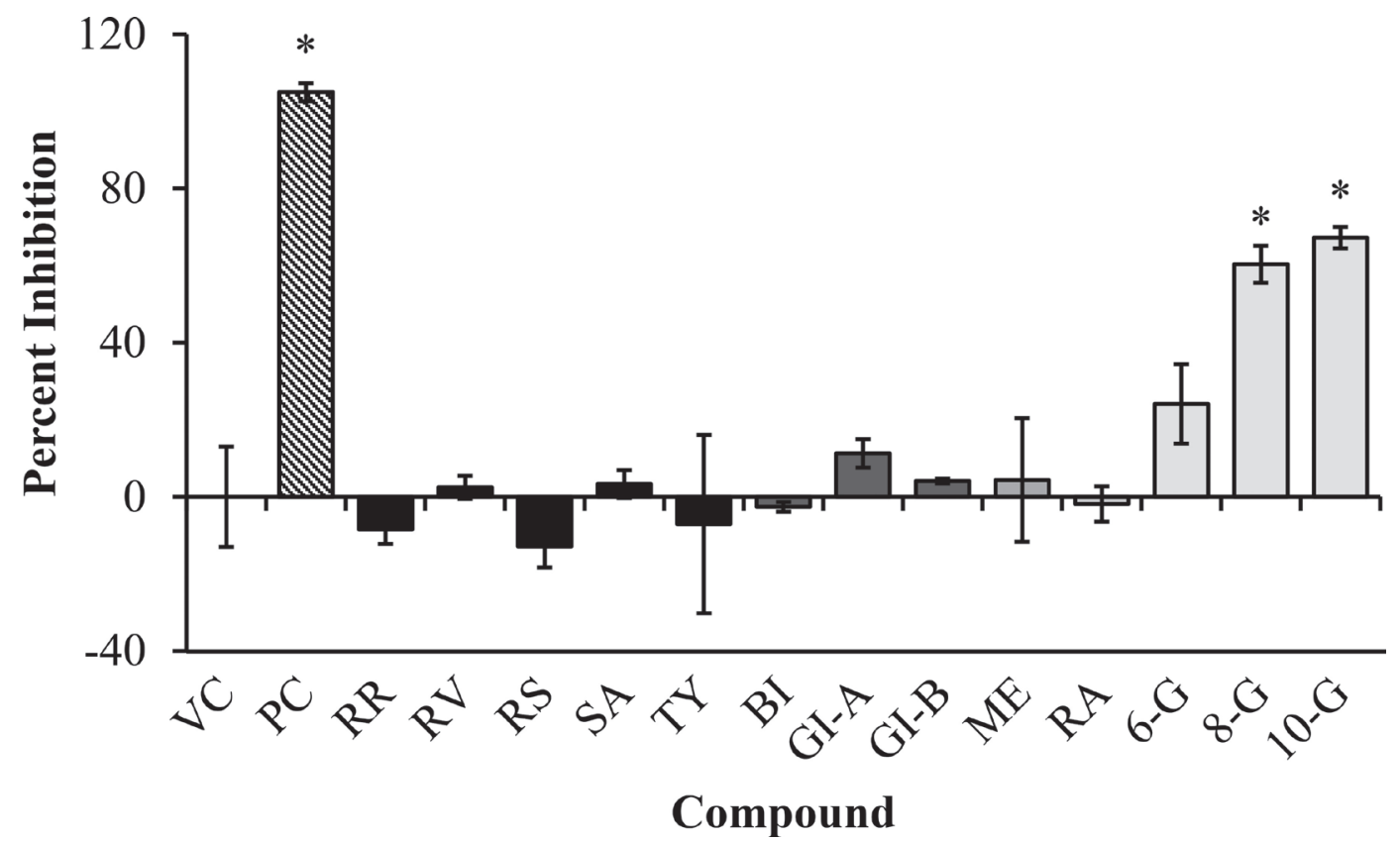

Figure 5. The inhibitory effect of marker compounds $(10 \mu \mathrm{g} / \mathrm{mL})$ of commercial herbal extracts on carboxylesterase 1 mediated metabolism of 4-nitrophenyl acetate. Means \pm SEM are presented for three independent trials. JZL184 (2 $\mu \mathrm{M}$ or $1 \mu \mathrm{g} / \mathrm{mL}$ ) was used as a positive control (PC). (RR) rosarin; (RV) rosarin; (RS) rosin; (SA) salidroside; (TY) tyrosol; (BI) bilobalide; (Gl-A) ginkgolide A; (GI-B) ginkgolide B; (ME) menthol; (RA) rosmarinic acid; (6-G) [6]-gingerol; (8-G) [8]-gingerol; (10-G) [10]-gingerol. A one-way ANOVA with Dunnett's multiple comparisons test was used to compare percent inhibition to vehicle control (2\% acetone final concentration) $* P<0.05$. 

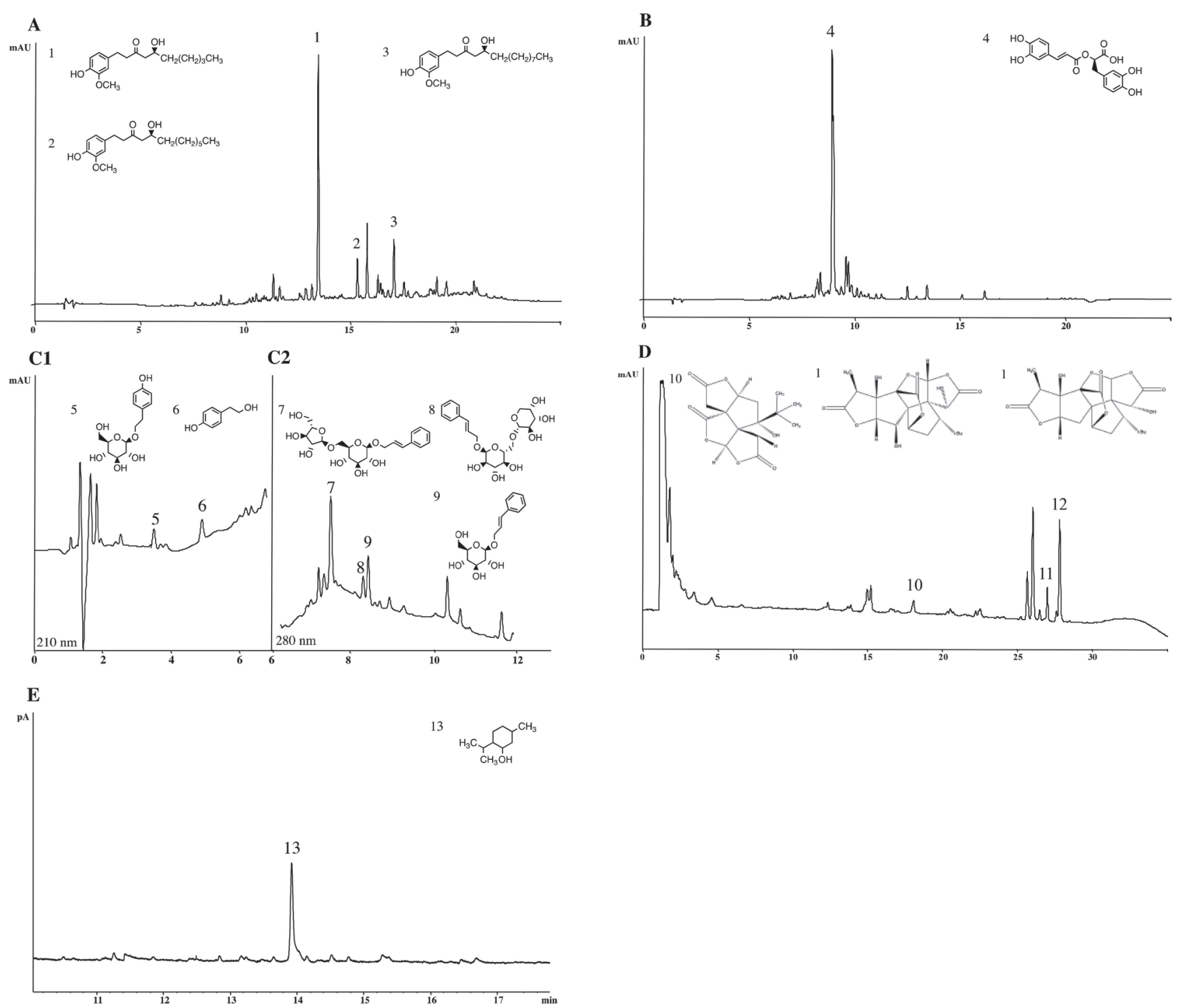

Figure 6. Identification of phytochemical marker compounds in the tested commercial extracts of ginger, rosemary, rhodiola, ginkgo, and peppermint. HPLC-DAD chromatogram of $10 \mathrm{mg} / \mathrm{mL}$ (A) ginger at 280 nm; (B) rosemary at $350 \mathrm{~nm}$; rhodiola at (C1) $210 \mathrm{~nm}$ and (C2) $280 \mathrm{~nm}$; (D) ginkgo at $220 \mathrm{~nm}$; and (E) gas chromatogram of commercial extract of peppermint $(1 \mathrm{mg} / \mathrm{mL})$. Peaks of marker compounds are identified as (1) [6]-gingerol; (2) [8]-gingerol; (3) [10]-gingerol; (4) rosmarinic acid; (5) salidroside; (6) tyrosol; (7) rosarin; (8) rosavin; (9) rosin; (10) bilobalide; (11) ginkgolide A; (12) ginkgolide B; and (13) menthol.

examined in this study have not yet been studied for their effects on CES1 inhibition.

Many of the 21 herbal medicine investigated in the current study have been tested in vitro for their effects on CYP 450 system. In the context of ADHD, CYP 2D6 and CYP 3A4 are important enzymes involved in the metabolic pathways of ADHD drugs amphetamine, atomoxetine, and guanfacine [37, 38]. Previous studies report rhodiola [39, 40], St. John's wort [41, 42], goldenseal $[43,44]$ and kava $[45]$ to be moderate to strong inhibitors of CYP 2D6 and CYP 3A4. Green tea [46] and peppermint [47] were moderate to strong inhibitors of CYP 3A4. In the current study, these products showed potential for interaction with CES1 as inhibition ranged from $62 \%-93 \%$. Bacopa is a moderate inhibitor of CYP 3A4 [48], but did not show inhibition in our study. In general, herbal medicines known to inhibit CYP 3A4 and CYP 2D6 were among the moderate to stronger inhibitors of CES1 in our study.

Analyses of concentration-dependent and timedependent responses indicated that rhodiola was a reversible yet potent inhibitor of human CES1 and may pose a risk to individuals concurrently using conventional drugs, such as methylphenidate, that are substrates of CES1. Moreover, ginkgo, ginger, peppermint, and rosemary were mild reversible inhibitors of CES1 under these study conditions that may also pose a risk of interaction when used concurrently with 
CES1-substrate drugs. It is important to highlight that in vitro herb-drug interactions do not always translate to clinically relevant interactions, in part due to the supraphysiologic concentrations of inhibitor and substrate used in assays. However, they can demonstrate a potential for risk and provide better understanding of the mechanisms of herb-drug interactions to minimize and/or avoid therapeutic failures and toxicity.

The HPLC-DAD profile of rhodiola extract in this study confirmed the presence of marker compounds to which commercial rhodiola products are typically standardized, including salidroside, tyrosol, rosavin, rosin, and rosarin [49]. Considering the $\mathrm{IC}_{50}$, rhodiola was the most potent commercial product identified in our study, however, its marker constituents showed little to no activity at $10 \mu \mathrm{g} / \mathrm{mL}$. Moreover, rhodiola constituents did not show inhibition of various cytochrome P450 enzymes [39, 50, 51]. Hence, the tested marker compounds do not explain the observed CES1 inhibitory activity of the extract, meaning that the level of risk (for CES1 inhibition) cannot be determined based on the marker compounds labelled on the product. Additional research is needed to understand variation in the inhibition between various products of rhodiola, and identifying phytochemicals contributing to the inhibitory activity.

CES1 activates several ester containing prodrugs, such as antivirals (e.g. oseltamivir) and anti-hypertensive angiotensin-converting enzyme inhibitor drugs (e.g. imidapril), and inactivates many other therapeutic agents including anti-epileptic drugs (e.g. rufinamide), and antithrombotic drugs (e.g. clopidogrel) [28, 52-54]. Like methylphenidate, the risk of herb-drug interaction for patients taking these therapeutic agents is elevated, especially for those patients who practice polypharmacy. Patients taking CES1 substrate drugs with a narrow therapeutic index (e.g. clopidogrel and irinotecan) are particularly susceptible to clinically relevant pharmacokinetic herb-drug interactions $[55,56]$. Studies reported CES1 polymorphisms resulting in reduced ability to hydrolyze CES1 substrates including methylphenidate, clopidogrel, and oseltamivir [51, 57, 58]. Reduction in enzyme activity can result in an increase in the concentration of active parent drugs leading to potential toxic effects, and poor efficacy for prodrugs requiring activation through CES1. It is important to note that not all pharmacokinetic herb-drug interactions result in adverse effects in patients. However, individuals with CES1 polymorphisms utilizing herbal medicine that we identified as CES1 inhibitors may have an increased risk of changes in drug pharmacokinetics leading to clinically significant adverse effects.

\section{Conclusions}

Considering the overall observed CES1 inhibition by extracts, the concurrent use of methylphenidate (and other CES1 substrate drugs) with herbal medicine tested, in general, is likely safe. However, patients using higher or frequent doses of herbal medicine (especially of ginkgo, rhodiola, peppermint, rosemary, and ginger products) are at higher risk of herb-drug interactions and should monitor their AEs. It is also fundamental for patients to communicate with their healthcare professionals about the use of herbal medicine, and for healthcare practitioners to routinely inquire about the use of these products. Healthcare professionals should gain familiarity about the effects of concurrent use of popular herbs with therapeutic drugs to provide evidence-based information to patients.

\section{List of Abbreviations}

\author{
4-NA: 4-nitrophenyl acetate \\ ADHD: attention deficit hyperactivity disorder \\ AEs: adverse events \\ CES1: carboxylesterase-1 \\ CYP 2D6: cytochrome 2D6 \\ CYP 3A4: cytochrome 3A4 \\ CYP P450: cytochrome P450 \\ GC-FID: gas chromatography flame-ionized detection \\ HPLC-DAD: high performance liquid chromatography \\ diode array detector \\ $\mathrm{IC}_{50}$ : half maximal inhibitory concentration \\ $K_{i}$ : inhibitory constant \\ NHP: natural health product \\ UV: ultraviolet \\ VC: vehicle control
}

\section{Authors' Contributions}

CSH: contributed to the design of the study, data analysis, revised and approved the final manuscript.

HM: contributed to the design of the study, data collection and analysis, drafted, revised, and approved the final manuscript.

PR: contributed to the design of the study, revised, and approved the final manuscript

\section{Acknowledgements}

The authors would like to thank St. Francis Herb Farm for providing the herbal tinctures. We would like to thank Saipranay Guntaka, Evan Trofimchuk, and Mahdi Mahallati for the dried extract preparations. We would also like to thank Rui Liu for his help with training with 
the assay procedures and phytochemical analysis. The authors acknowledge Dr. Brian Foster for his assistance in reviewing the manuscript.

\section{Funding}

This research was supported by a Natural Science and Engineering Research Council of Canada Discovery Grant and a University of Ottawa Research Development Grant (CSH).

\section{References}

[1] Polanczyk G, De Lima MS, Horta BL, Biederman J, Rohde LA. The worldwide prevalence of ADHD: a systematic review and metaregression analysis. Am J Psychiatry. 2007;164(6):942-8. http://doi.org/10.1176/ ajp.2007.164.6.942

[2] Thomas R, Sanders S, Doust J, Beller E, Glasziou P. Prevalence of attention-deficit/hyperactivity disorder: a systematic review and meta-analysis. Pediatrics. 2015;135(4):e994-1001. http://doi.org/10.1542/ peds.2014-3482

[3] StevensJR, Wilens TE, Stern TA. Using stimulants for attention-deficit/hyperactivity disorder: clinical approaches and challenges. Prim care companion CNS Disord. 2013;15(2). http://doi.org/10.4088/PCC.12f01472

[4] Teva Canada Limited. PRODUCT MONOGRAPH: ACT AMPHETAMINE XR. 2015.

[5] Sun Z, Murry DJ, Sanghani SP, Davis WI, Kedishvili NY, Zou Q, et al. Methylphenidate is stereoselectively hydrolyzed by human carboxylesterase CES1A1. J Pharmacol Exp Ther. 2004;310(2):469-76. http://doi.org/10.1124/ jpet.104.067116

[6] Cygler M, Schrag JD, Sussman JL, Harel M, Silman I, Gentry MK, et al. Relationship between sequence conservation and three-dimensional structure in a large family of esterases, lipases, and related proteins. Protein Sci. 1993;2(3):366-82. http://doi.org/10.1002/ pro.5560020309

[7] Casey Laizure S, Herring V, Hu Z, Witbrodt K, Parker RB. The role of human carboxylesterases in drug metabolism: have we overlooked their importance? Pharmacother J Hum Pharmacol Drug Ther. 2013;33(2):210-22. http:// doi.org/10.1002/phar.1194

[8] Satoh T, Hosokawa M. The mammalian carboxylesterases: from molecules to functions. Annu Rev Pharmacol Toxicol. 1998;38(1):257-88. http://doi.org/10.1146/ annurev.pharmtox.38.1.257

[9] Sanghani SP, Sanghani PC, Schiel MA, Bosron WF. Human carboxylesterases: an update on CES1, CES2 and CES3. Protein Pept Lett. 2009;16(10):1207-14. http://doi.org/10.2174/092986609789071324
[10] Imai T. Human carboxylesterase isozymes: catalytic properties and rational drug design. Drug Metab Pharmacokinet. 2006;21(3):173-85. http://doi. org/10.2133/dmpk.21.173

[11] Sinha D, Efron D. Complementary and alternative medicine use in children with attention deficit hyperactivity disorder. J Paediatr Child Health. 2005;41(1-2):23-6. http://doi.org/10.1111/j.1440-1754.2005.00530.x

[12] Galicia-Connolly E, Adams D, Bateman J, Dagenais S, Clifford T, Baydala L, et al. CAM use in pediatric neurology: an exploration of concurrent use with conventional medicine. PLoS One. 2014;9(4):e94078. http://doi. org/10.1371/journal.pone.0094078

[13] World Health Organization. National policy on traditional medicine and regulation of herbal medicines: Report of a WHO global survey. 2005.

[14] Mazhar H, Harkin EF, Foster BC, Harris CS. Complementary and alternative medicine use in pediatric attention-deficit hyperactivity disorder (ADHD): Reviewing the safety and efficacy of herbal medicines. Curr Dev Disord Reports. 2016;3(1):15-24. http://doi. org/10.1007/s40474-016-0074-x

[15] Blumenthal M, Goldberg A, Brinckmann J. Herbal Medicine. Expanded Commission E monographs. Integrative Medicine Communications; 2000.

[16] Gurley BJ, Gardner SF, Hubbard MA, Williams DK, Gentry WB, Khan IA, et al. In vivo effects of goldenseal, kava kava, black cohosh, and valerian on human cytochrome P450 1A2,2D6,2E1, and3A4/5phenotypes. ClinPharmacolTher. 2005;77(5):415-26. http://doi.org/10.1016/j.clpt.2005. 01.009

[17] Xu J, Qiu J-C, Ji X, Guo H-L, Wang X, Zhang B, et al. Potential Pharmacokinetic Herb-Drug Interactions: Have we Overlooked the Importance of Human Carboxylesterases 1 and 2? Curr Drug Metab. 2019;20(2):130-7. http://doi. org/10.2174/1389200219666180330124050

[18] Sun D-X, Ge G-B, Dong P-P, Cao Y-F, Fu Z-W, Ran R-X, et al. Inhibition behavior of fructus psoraleae's ingredients towards human carboxylesterase 1 (hCES1). Xenobiotica. 2016;46(6):503-10. http://doi.org/10.3109 /00498254.2015.1091521

[19] Zou L-W, Dou T-Y, Wang P, Lei W, Weng Z-M, Hou $J$, et al. Structure-activity relationships of pentacyclic triterpenoids as potent and selective inhibitors against human carboxylesterase 1. Front Pharmacol. 2017;8:435. http://doi.org/10.3389/fphar.2017.00435

[20] Gorman GS, Coward L, Darby A, Rasberry B. Effects of herbal supplements on the bioactivation of chemotherapeutic agents. J Pharm Pharmacol. 2013;65(7): 1014-25. http://doi.org/10.1111/jphp.12055

[21] Liu R, Tam TW, Mao J, Saleem A, Krantis A, Arnason JT, et al. The effect of natural health products and traditional medicines on the activity of human hepatic 
microsomal-mediated metabolism of oseltamivir. J Pharm Pharm Sci. 2010;13(1):43-55. http://doi. org/10.18433/J3ZP42

[22] Iwata H, Tezuka Y, Kadota S, Hiratsuka A, Watabe T. Mechanism-based inactivation of human liver microsomal CYP3A4 by rutaecarpine and limonin from Evodia fruit extract. Drug Metab Pharmacokinet. 2005;20(1): 34-45. http://doi.org/10.2133/dmpk.20.34

[23] Grimm SW, Einolf HJ, Hall SD, He K, Lim H-K, Ling K-HJ, et al. The conduct of in vitro studies to address time-dependent inhibition of drug-metabolizing enzymes: a perspective of the pharmaceutical research and manufacturers of America. Drug Metab Dispos. 2009;37(7):1355-70. http://doi.org/10.1124/dmd.109.026716

[24] Paine MF, Criss AB, Watkins PB. Two major grapefruit juice components differ in time to onset of intestinal CYP3A4 inhibition. J Pharmacol Exp Ther. 2005;312(3):1151-60. http://doi.org/10.1124/jpet.104.076836

[25] Yan B. Hydrolytic enzymes. Metab Drugs other Xenobiotics. 2012;165-98. http://doi.org/10.1002/9783527630905.ch6

[26] Bachovchin DA, Ji T, Li W, Simon GM, Blankman JL, Adibekian A, et al. Superfamily-wide portrait of serine hydrolase inhibition achieved by library-versus-library screening. Proc Natl Acad Sci. 2010;107(49):20941-6. http://doi.org/10.1073/pnas.1011663107

[27] Crow JA, Bittles V, Borazjani A, Potter PM, Ross MK. Covalent inhibition of recombinant human carboxylesterase 1 and 2 and monoacylglycerol lipase by the carbamates JZL184 and URB597. Biochem Pharmacol. 2012;84(9):1215-22. http://doi.org/10.1016/j.bcp.2012. 08.017

[28] Shi D, Yang J, Yang D, LeCluyse EL, Black C, You L, et al. Anti-influenza prodrug oseltamivir is activated by carboxylesterase human carboxylesterase 1, and the activation is inhibited by antiplatelet agent clopidogrel. J Pharmacol Exp Ther. 2006;319(3):1477-84. http://doi. org/10.1124/jpet.106.111807

[29] Ajandouz EH, Berdah S, Moutardier V, Bege T, Birnbaum DJ, Perrier J, et al. Hydrolytic fate of 3/15-acetyldeoxynivalenol in humans: Specific deacetylation by the small intestine and liver revealed using in vitro and ex vivo approaches. Toxins (Basel). 2016;8(8):232. http://doi. org/10.3390/toxins8080232

[30] Murakami E, Tolstykh T, Bao H, Niu C, Steuer HMM, Bao D, et al. Mechanism of activation of PSI-7851 and its diastereoisomer PSI-7977. J Biol Chem. 2010;285(45): 34337-47. http://doi.org/10.1074/jbc.M110.161802

[31] Yamamoto T, Suzuki A, Kohno Y. Application of microtiter plate assay to evaluate inhibitory effects of various compounds on nine cytochrome P450 isoforms and to estimate their inhibition patterns. Drug Metab Pharmacokinet. 2002;17(5):437-48. http://doi. org/10.2133/dmpk.17.437
[32] Lee T. Cannabis Metabolomics: Comparison of Cannabis Products and Effect of Vaporization. Université d'Ottawa/ University of Ottawa; 2019. http://doi.org/10.20381/ ruor-23949

[33] Chen F, Ji X, Qiu J-C, Zhang B, Wang X, Guo H-L, et al. Potential pharmacokinetic herb-drug interactions: have we overlooked the importance of human carboxylesterases 1 and 2? Curr Drug Metab. 2018;20(2):p. 130-37. http://doi.org/10.2174/1389200219666180330124050

[34] Mazhar H, Foster BC, Necyk C, Gardiner PM, Harris CS, Robaey P. Natural Health Product-Drug Interaction Causality Assessment in Pediatric Adverse Event Reports Associated with Attention-Deficit/Hyperactivity Disorder Medication. J Child Adolesc Psychopharmacol. 2019; 30(1):p.38-47. http://doi.org/10.1089/cap.2019.0102

[35] Foster BC, Vandenhoek S, Tang R, Budzinski JW, Krantis A, Li KY. Effect of several Chinese natural health products of human cytochrome P450 metabolism. J Pharm Pharm Sci. 2002;5(2):185-9. https://pubmed.ncbi.nlm. nih.gov/12207872/

[36] Zhang AL, Xue CC, Fong HHS. Chapter 22: Integration of Herbal Medicine into Evidence-Based Clinical Practice. Herb Med Biomol Clin Asp. 2011;1-15. 2011.

[37] Ring BJ, Gillespie JS, Eckstein JA, Wrighton SA. Identification of the human cytochromes P450 responsible for atomoxetine metabolism. Drug Metab Dispos. 2002;30(3):319-23. http://doi.org/10.1124/ dmd.30.3.319

[38] Bach MV, Coutts RT, Baker GB. Involvement of CYP2D6 in the in vitro metabolism of amphetamine, two $\mathrm{N}$-alkylamphetamines and their 4-methoxylated derivatives. Xenobiotica. 1999;29(7):719-32. http://doi. org/10.1080/004982599238344

[39] Hellum BH, Tosse A, Hoybakk K, Thomsen M, Rohloff J, Nilsen OG. Potent in vitro inhibition of CYP3A4 and P-glycoprotein by Rhodiola rosea. Planta Med. 2010;76(04):331-8. DOI: 10.1055/s-0029-1186153

[40] Xu W, Zhang T, Wang Z, Liu T, Liu Y, Cao Z, et al. Two potent cytochrome P450 2D6 inhibitors found in Rhodiola rosea. Die Pharm Int J Pharm Sci. 2013;68(12):974-6. DOI: 10.1691/ph.2013.3593

[41] Komoroski BJ, Zhang S, Cai H, Hutzler JM, Frye R, Tracy TS, et al. Induction and inhibition of cytochromes P450 by the St. John's wort constituent hyperforin in human hepatocyte cultures. Drug Metab Dispos. 2004;32(5):512-8. http://doi.org/10.1124/dmd.32.5.512

[42] Obach RS. Inhibition of human cytochrome P450 enzymes by constituents of St. John's Wort, an herbal preparation used in the treatment of depression. J Pharmacol Exp Ther. 2000;294(1):88-95. https:// pubmed.ncbi.nlm.nih.gov/10871299/

[43] Chatterjee P, Franklin MR. Human cytochrome p450 inhibition and metabolic-intermediate complex formation 
by goldenseal extract and its methylenedioxyphenyl components. Drug Metab Dispos. 2003;31(11):1391-7. http://doi.org/10.1124/dmd.31.11.1391

[44] Sevior DK, Hokkanen J, Tolonen A, Abass K, Tursas L, Pelkonen $\mathrm{O}$, et al. Rapid screening of commercially available herbal products for the inhibition of major human hepatic cytochrome P450 enzymes using the N-in-one cocktail. Xenobiotica. 2010;40(4):245-54. http://doi. org/10.3109/00498251003592683

[45] Mathews JM, Etheridge AS, Black SR. Inhibition of human cytochrome P450 activities by kava extract and kavalactones. Drug Metab Dispos. 2002;30(11):1153-7. http:// doi.org/10.1124/dmd.30.11.1153

[46] Misaka S, Kawabe K, Onoue S, Werba JP, Giroli M, Tamaki $S$, et al. Effects of green tea catechins on cytochrome P450 2B6, 2C8, 2C19, 2D6 and 3A activities in human liver and intestinal microsomes. Drug Metab Pharmacokinet. 2012;DMPK-12. http://doi.org/10.2133/ dmpk.DMPK-12-RG-101

[47] Dresser GK, Wacher V, Wong S, Wong HT, Bailey DG. Evaluation of peppermint oil and ascorbyl palmitate as inhibitors of cytochrome P4503A4 activity in vitro and in vivo. Clin Pharmacol Ther. 2002;72(3):247-55. http://doi. org/10.1067/mcp.2002.126409

[48] Ramasamy S, Kiew L, Chung L. Inhibition of human cytochrome P450 enzymes by Bacopa monnieri standardized extract and constituents. Molecules. 2014;19(2):2588-601. http://doi.org/10.3390/molecules 19022588

[49] Dimpfel W, Schombert L, Panossian AG. Assessing the quality and potential efficacy of commercial extracts of Rhodiola rosea L. by analyzing the salidroside and rosavin content and the electrophysiological activity in hippocampal long-term potentiation, a synaptic model of memory. Front Pharmacol. 2018;9:425. http://doi. org/10.3389/fphar.2018.00425

[50] Thu OK, Nilsen OG, Hellum B. In vitro inhibition of cytochrome P-450 activities and quantification of constituents in a selection of commercial Rhodiola rosea products. Pharm Biol. 2016;54(12):3249-56. http://doi. org/10.1080/13880209.2016.1223145
[51] Zhu H-J, Wang X, Gawronski BE, Brinda BJ, Angiolillo DJ, Markowitz JS. Carboxylesterase 1 as a determinant of clopidogrel metabolism and activation. J Pharmacol Exp Ther. 2013;344(3):665-72. http://doi.org/10.1124/ jpet.112.201640

[52] T Williams E, Eric Carlson J, George Lai W, Nancy Wong Y, Yoshimura T, J Critchley D, et al. Investigation of the metabolism of rufinamide and its interaction with valproate. Drug Metab Lett. 2011;5(4):280-9. http://doi. org/10.2174/187231211798472511

[53] Takai S, Matsuda A, Usami Y, Adachi T, Sugiyama T, Katagiri $Y$, et al. Hydrolytic profile for ester-or amidelinkage by carboxylesterases pl 5.3 and 4.5 from human liver. Biol Pharm Bull. 1997;20(8):869-73. http://doi. org/10.1248/bpb.20.869

[54] Tang M, Mukundan M, Yang J, Charpentier N, LeCluyse EL, Black C, et al. Antiplatelet agents aspirin and clopidogrel are hydrolyzed by distinct carboxylesterases, and clopidogrel is transesterificated in the presence of ethyl alcohol. J Pharmacol Exp Ther. 2006;319(3):1467-76. http://doi.org/10.1124/jpet.106.110577

[55] Laizure SC, Mandrell T, Gades NM, Parker RB. Cocaethylene metabolism and interaction with cocaine and ethanol: role of carboxylesterases. Drug Metab Dispos. 2003;31(1):16-20. DOI: https://doi.org/10.1124/ dmd.31.1.16

[56] Innocenti F, Kroetz DL, Schuetz E, Dolan ME, Ramírez J, Relling $\mathrm{M}$, et al. Comprehensive pharmacogenetic analysis of irinotecan neutropenia and pharmacokinetics. J Clin Oncol. 2009;27(16):2604. http://doi.org/10.1200/ JCO.2008.20.6300

[57] Zhu H-J, Markowitz JS. Activation of the antiviral prodrug oseltamivir is impaired by two newly identified carboxylesterase 1 variants. Drug Metab Dispos. 2009;37(2): 264-7. http://doi.org/10.1124/dmd.108.024943

[58] Zhu H-J, Wang J-S, DonovanJL, Jiang Y, Gibson BB, DeVane $C L$, et al. Interactions of attention-deficit/hyperactivity disorder therapeutic agents with the efflux transporter P-glycoprotein. Eur J Pharmacol. 2008;578(2-3):148-58. http://doi.org/10.1016/j.ejphar.2007.09.035 


\section{Article Information}

Managing Editor: Kieran Cooley

Peer Reviewers: Gyana Ranjan Rout, Frederic Calon

Article Dates: Received Jul 10 20; Accepted Nov 09 20; Published Jan 1921

\section{Citation}

Please cite this article as follows:

Mazhar H, Robaey P, Harris CS. An In Vitro Evaluation of the Inhibition of Recombinant Human Carboxylesterase-1 by Herbal Extracts. Journal of Natural Health Product Research. 2021 Jan 19: 3(1). https://jnhpresearch.com/index. php/jnhpr/article/view/11

DOI Link: https://doi.org/10.33211/jnhpr.11

\section{Copyright}

(c) Hajra Mazhar, Philippe Robaey, Cory S. Harris. (2021). Published first in the Journal of Natural Health Product Research. This is an open access article distributed under the terms of the Creative Commons Attribution License (https://creativecommons.org/licenses/by/4.0/), which permits unrestricted use, distribution, and reproduction in any medium, provided the original work, first published in the Journal of Natural Health Product Research, an NHP Publications journal, is properly cited. The complete bibliographic information, a link to the original publication on https://www.jnhpresearch.com, as well as this copyright and license information must be included.

Journal of Natural Health Product Research
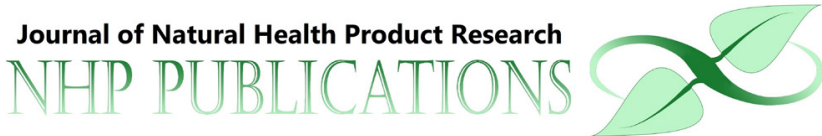

Canadà

Does the safety, efficacy, and quality of natural health products matter to YOU? Submit your research article to the Journal of Natural Health Product Research!

Pre-submission inquiries? Send us an email at editorial.office@jnhpresearch.com Facebook, Twitter and LinkedIn: @NHPPublications 